\title{
Field Case 3: Oman: Thermal Steam Production of 100,000 cP Oil
}

\section{Dawood Al-Qassabi, PDO}

A thermal steam trial is applied in a multi-billion barrel STOIIP oilfield with very complex reservoir and oil properties. With low permeability, and saturation, deep thinly laminated formation and ultra heavy oil viscosity $\left(100,000 \mathrm{cp}\right.$ at reservoir temperature of $\left.65^{\circ} \mathrm{C}\right)$, the field introduces extreme challenges for conventional thermal development. This requires innovative solutions to stretch the thermal development boundaries to achieve technical and commercial success. In order to accommodate such subsurface challenges, unique surface facilities were acquired which made it possible to inject heat at high pressures.

The trial consists of two main phases; Phase 1 where steam is injected and back-produced with oil from the same well i.e. Cyclic Steam Stimulation (CSS), and Phase 2 where steam flooding is to be tested in an inverted 5 spot pattern. Currently, the trial completed Phase 1 with four CSS cycles.

Despite all these challenges, Phase 1 of the trial successfully conducted 4 cyclic steam stimulation cycles where over 13,000 tons Cold Water Equivalent (CWE) were injected into the formation at high pressure $(21,000 \mathrm{Kpa})$ and high temperature $\left(360^{\circ} \mathrm{C}\right)$ environment. The trial has confirmed injectivity into the deep and tight formation and proved the productivity of its ultra heavy oil trucked to production station via special heated trucks. Extensive surveillance activities were performed including 11 PLT runs during injection, soaking and free-flow periods, making such success an industry-first in the region. The PLT runs confirmed delivering heat of $300^{\circ} \mathrm{C}$ to reservoir level and conformable vertical distribution of steam injection across the reservoir. 